\section{Micropropagation of Tolumnia Orchids through Induction of Protocorm-like Bodies from Leaf Segments}

\author{
Nittaya Chookoh, Yi-Tien Chiu, and Chen Chang ${ }^{1}$ \\ Department of Horticulture, National Chung Hsing University, 145, Xingda \\ Road, South District, 402 Taichung, Taiwan, ROC
}

\section{Wei-Hsin Hu}

Department of Biology, National Museum of Natural Science, 1 Guancian Road, Taichung 404, Taiwan, ROC

\section{Ting-En Dai \\ Floriculture Research Center, Taiwan Agricultural Research Institute, 646 Yunlin, Taiwan, ROC}

Additional index words. flower stalk culture, leaf culture, protocorm-like body, PLB induction, plant regeneration

\begin{abstract}
A protocol for plant regeneration via direct induction of protocorm-like bodies (PLBs) from leaf segments of Tolumnia Snow Fairy was developed as a basis for mass production. Ten-month-old, in vitro-grown donor plantlets were obtained by inducing shoots from buds on the flower stalk. Leaf segments harvested from plantlets of different heights and from expanding leaves at different positions were compared, as were two BA concentrations with $0.5 \mathrm{mg} \cdot \mathrm{L}^{-1}$ NAA. The greatest rate of PLB induction $(16.7 \%)$ was observed when leaf segments taken from $1-$ to $2-\mathrm{cm}$ height plants were cultured in Murashige and Skoog (MS) basal medium supplemented with $2 \mathrm{mg} \cdot \mathrm{L}^{-1}$ BA and 0.5 mg. $\mathrm{L}^{-1}$ NAA after 16 weeks of culture. When using leaf explants, only inner, expanding leaves cultured on MS basal medium supplemented with $4 \mathrm{mg} \cdot \mathrm{L}^{-1} \mathrm{BA}$ and $0.5 \mathrm{mg} \cdot \mathrm{L}^{-1}$ NAA resulted in PLB induction, at an average rate of 25.5 PLBs per explant. After 16 weeks of culture, histological and scanning electron microscopy (SEM) observations revealed that PLBs originated from epidermal cells of leaf explants. PLBs of 1 to $\leq 2 \mathrm{~mm}$ in diameter continued to proliferate after 4 weeks of culture. These secondary PLBs could be produced from either whole PLBs or the upper side of PLBs. Finally, PLBs were regenerated into plantlets. After $\approx 14$ months of culture, fully developed plants exhibiting well-developed roots and shoots were acclimatized. These plants grew well, with 1-year survival rates of nearly $73 \%$, for plants originating as explants taken from 1 - to 2 -cm tall plants, and of $79 \%$, for plants originating as explants taken from inner leaves. Some mature plants flowered 1 year after transplantation. This study presents a simple system that can provide a large number of PLBs for mass propagation in a short time that can be converted into plants and also used for the new cultivars of Tolumnia orchids.
\end{abstract}

The group of orchids now called tolumnia was once called Oncidium section Variegata and was commonly referred to as the "equitant oncidiums" (Aldrich, 1994). Plants in this genus are endemic to the Caribbean

Received for publication 19 Nov. 2018. Accepted for publication $20 \mathrm{Feb} .2019$.

This work was partial supported by grants from National Chung Hsing University and Agricultural Research Institute, Council of Agriculture, Executive of Yuan, ROC NCHU-TARI 10607) Taichung, Taiwan, Republic of China, and in part by the Advanced Plant Biotechnology Center from The Featured Areas Research Center Program within the framework of the Higher Education Sprout Project by the Ministry of Education (MOE) in Taiwan.

${ }^{1}$ Corresponding author. E-mail: chenchang@dragon. nchu.edu.tw.

This is an open access article distributed under the CC BY-NC-ND license (http://creativecommons.org/ licenses/by-nc-nd/4.0/). mother plant (Chugh et al., 2009; De and Sil, 2015), and are available in any season, unlike inflorescence explants (Chugh et al., 2009). Presently, commercial growers of most orchid genera prefer propagation through PLB formation because of the large number of PLBs that can be achieved within a relatively short period of time using this method (Antony et al., 2014; Ng et al., 2010). Plant regeneration through PLB induction from leaf explants has been developed for Acampe (Nayak et al., 1997), Aerides (Murthy, 2005; Murthy and Pyati, 2001), Coelogyne (De and Sil, 2015), Dendrobium (Chung et al., 2005, 2007; Goswami et al., 2015; Martin and Madassery, 2006), Oncidium (Balilashaki et al., 2015; Chen and Chang, 2001, 2003, 2004; Chen and Hong, 2012; Chen et al., 1999; Chung et al., 2010; Hong et al., 2008; Mata-Rosas et al., 2011; Mayer et al., 2010; Mengxi et al., 2011), Phalaenopsis (Chen and Chang, 2006; Gow et al., 2009; Kuo et al., 2005; Park et al., 2002a, 2002b), Spathoglottis (Teng et al., 1997), Vanda (Decruse et al., 2003), and Vanilla (Janarthanam and Seshadri, 2008; Tan et al., 2011). In tissue culture, cytokinins are a group of hormones that promote cell division, especially; BA is widely used for tissue culture research because of its low price and effectiveness (George et al., 2008).

Until now, there have only been a few reports describing PLB induction in tolumnia orchids (Shen et al., 2018). However, not all of cultivars can respond to the same protocol under the same culture conditions. In this study, we describe a simple and suitable protocol for clonal propagation of tolumnia orchids from leaf segments via PLB induction. After PLB induction, PLBs were used for further proliferation via a PLB bisection method. PLBs were converted into plantlets and then full plants, which were then acclimatized and allowed to flower.

\section{Materials and Methods}

Initiation of in vitro-grown donor plantlets. Tissue culture materials were obtained from the flower stalk nodes of the Tolumnia cultivar Snow Fairy (in vivo-grown) (Fig. 1A). After 10-month-old, in vitro-grown donor plantlets of Tolumnia Snow Fairy were obtained (Chookoh, 2015; Chookoh et al., 2016) (Fig. 1B-C). Leaves from these in vitro donor plantlets were used as explants for further experiments (Fig. 1D) and to evaluate the effects that plant height and leaf position at the time of leaf harvesting had on PLB induction.

Leaf culture medium and growth conditions. For the culture of leaf segments, MS basal medium (Murashige and Skoog, 1962) modified with half-strength mineral macroelements and microelements and apart from full-strength $\mathrm{NaFe}$-EDTA and $\mathrm{FeSO} 4$, vitamins, and glycine, containing $100 \mathrm{mg} \cdot \mathrm{L}^{-1}$ myo-inositol (Sigma-Aldrich Co., St. Louis, MO), $170 \mathrm{mg} \cdot \mathrm{L}^{-1} \mathrm{NaH}_{2} \mathrm{PO}_{4}$ (Hayashi Pure Chemical Ind., Co., Ltd., Osaka City, Japan), $30 \mathrm{~g} \cdot \mathrm{L}^{-1}$ sucrose (Taiwan Sugar Corporation, 


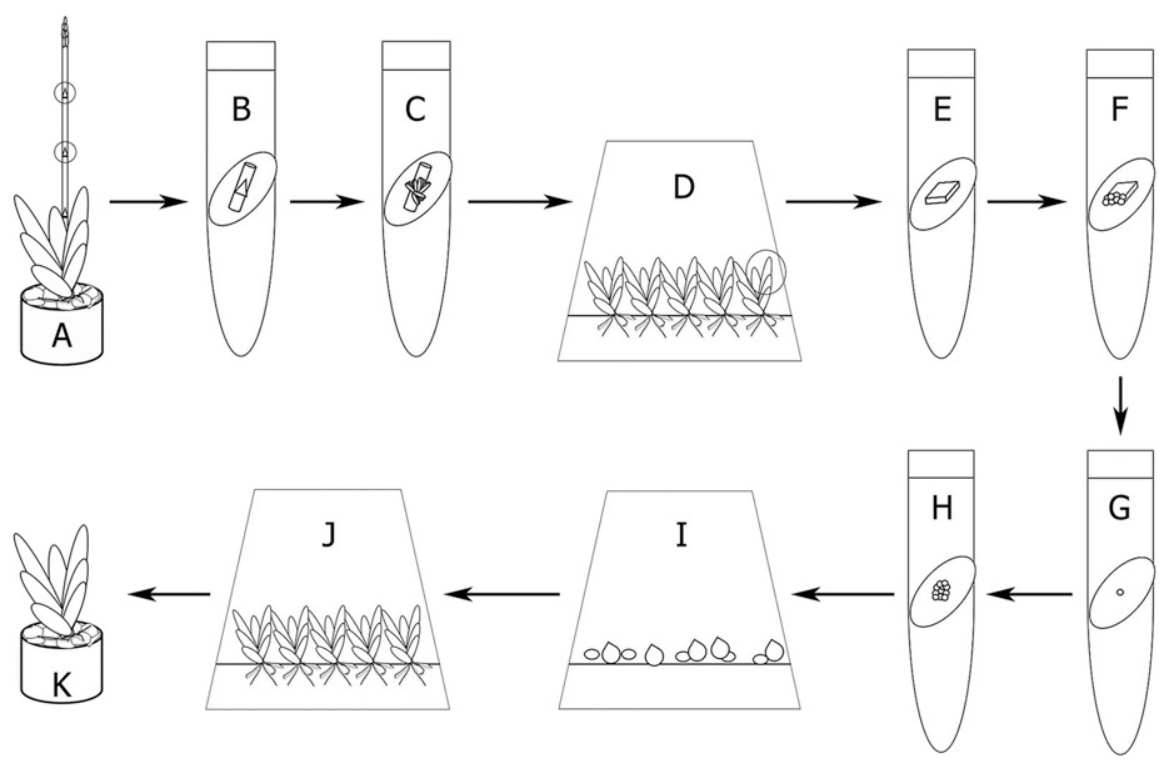

Fig. 1. Flow chart of micropropagation of Tolumnia Snow Fairy orchids through induction of protocormlike bodies (PLBs) from leaf segments. (A) Pot-grown mother plant with flower stalk; (B) flower stalks were excised, sterilized, and placed on shoot induction medium; (C) multiple shoots on shoot induction medium; (D) shoots on regeneration medium; (E) leaf segments were excised from in vitro-grown donor plantlets of different heights and from different positions (inner vs. outer leaves) and placed on PLB induction medium; (F) PLBs forming on PLB induction medium, which were separated for G; (G) single PLB on PLB proliferation medium; (H) PLB proliferation; (I) PLBs convert into plantlets; (J) plantlets were acclimated after three rounds of subculture; and (K) mature plant.

Tainan City, Taiwan), and $8 \mathrm{~g} \cdot \mathrm{L}^{-1}$ agar (Trade Mark, Tainan City, Taiwan) were prepared. The $\mathrm{pH}$ of the medium was adjusted to 5.2 with $0.1 \mathrm{~N} \mathrm{NaOH}$ or $\mathrm{HCl}$ before autoclaving. The medium $(10 \mathrm{~mL})$ was dispensed into culture tubes $(20 \times 15 \mathrm{~mm}$; PYREX Glass Test Tube 9820; Corning, USA). The culture vials containing the medium were autoclaved with $1.2 \mathrm{~kg} / \mathrm{cm}^{2}$ of pressure at $121{ }^{\circ} \mathrm{C}$ for $20 \mathrm{~min}$.

Leaf segments were placed horizontally on the surface (one explant per tube) of this MS basal medium. All cultures were maintained in a culture room at $25 \pm 2{ }^{\circ} \mathrm{C}$ for 8 weeks in the dark. After 8 weeks of culture, they were transferred to dim light $\left(5 \mu \mathrm{mol} \cdot \mathrm{m}^{-2} \cdot \mathrm{s}^{-1}\right.$ photosynthetic photon flux density) provided by cool white fluorescent tubes under a 12-h photoperiod (China Electric Manufacturing Corporation, Taipei, Taiwan).

Effects of plant height, leaf position, and $B A$ concentration on PLB induction from leaf explants. To investigate the effects of the height $(1-2,2-3$, and $3-4 \mathrm{~cm})$ of the in vitrogrown donor plantlets (Fig. 1D) on the efficiency of PLB induction, leaves were excised into three segments as tip, middle, and basal section $(3-5 \mathrm{~mm})$ from a random leaf's positions on plantlets of differing heights and cultured on MS basal medium supplemented with $0.5 \mathrm{mg} \cdot \mathrm{L}^{-1} 1$-Naphthaleneacetic acid (NAA) and 2 or $4 \mathrm{mg} \cdot \mathrm{L}^{-1}$ 6-Benzylaminopurine (BA) (Fig. 1E).

Leaves from plants bearing one to six visible leaves $(\approx 1-2 \mathrm{~cm}$ in height) were excised to investigate the effect of leaf position-inner (expanding leaves at first to third positions) or outer (expanding leaves at fourth to sixth positions) on PLB induction efficiency. Inner- and outer-leaf explants were excised into three segments as tip, middle, and basal part $(3-5 \mathrm{~mm})$ and cultured in MS basal medium supplemented 0.5 $\mathrm{mg} \cdot \mathrm{L}^{-1} \mathrm{NAA}$ and 2 or $4 \mathrm{mg} \cdot \mathrm{L}^{-1} \mathrm{BA}$.

For each of these treatments, $\approx 30$ leaf segments were cultured. One explant was inoculated in each culture vial, and five test tubes were considered one replication. Six replications were established for each treatment. Explants were subcultured to fresh medium every 4 weeks during the culture period. After 16 weeks of culture, PLB induction rate, necrotic explant rate, and the number of PLBs per explant were recorded. Cultures were examined and photographed with a stereozoom microscope (SZH; Olympus, Tokyo, Japan).

Histology of PLBs induced from leaf explants. PLBs still attached to leaf were fixed in $2 \%$ paraformaldehyde and $2.5 \%$ glutaraldehyde in $0.1 \mathrm{M}$ phosphate buffer $\left(\mathrm{pH} 6.8\right.$, at $4{ }^{\circ} \mathrm{C}$ overnight), dehydrated in an ethanol series, and embedded in Technovit 7100 resin (Kulzer \& Co., Wehrheim, Germany) as described by Yeung and Chan (2015). Serial sections (3$\mu \mathrm{m}$ thick) were cut using a rotary microtome (RM2245; Leica, Nussloch, Germany). Sections were stained with periodic acid-Schiff reagent for total insoluble carbohydrates and counterstained with amido black $10 \mathrm{~B}$ for proteins (Yeung, 1984). These sections were observed, and pictures were captured digitally using a charge-coupled device camera attached to the light microscope (Axiolab; Carl Zeiss Microscopy, GmbH, Jena, Germany).

SEM. For SEM, PLBs still attached to the leaf explant were fixed in $2.5 \%$ glutaralde- hyde in $0.1 \mathrm{M}$ phosphate buffer $(\mathrm{pH} 7.0$ ) for $4 \mathrm{~h}$ at $4{ }^{\circ} \mathrm{C}$, then dehydrated in an ethanol series, dried in a critical-point dryer (HCP-2, Hitachi, Japan), and finally coated with gold using an ion coater (E1010; Hitachi, Tokyo, Japan) (Chang et al., 2010). A scanning electron microscope (S-3000N; Hitachi) was used for examination and photography of the specimens.

Further proliferation of PLBS induced from leaf cultures. The PLBs that developed on leaf explants after 20 weeks were used as explants for PLB proliferation experiments (Fig. 1F). A stereo microscope was used for dividing the PLBs. PLB explants were placed on the surface (one explant per tube; Fig. 1G) of MS basal medium with one-eighth of $\mathrm{NH}_{4}$ $\mathrm{NO}_{3}$ and $\mathrm{KNO}_{3}$, half strength of the other strength mineral macroelements and microelements, and full strength of NaFe.EDTA, $\mathrm{FeSO}_{4}$, vitamins, and glycine. Most of contents were similar to the PLB induction medium, whereas proliferation medium was added containing $20 \mathrm{~g} \cdot \mathrm{L}^{-1}$ sucrose, $150 \mathrm{~mL} \cdot \mathrm{L}^{-1}$ coconut water, $1 \mathrm{~g} \cdot \mathrm{L}^{-1}$ peptone, $6 \mathrm{~g} \cdot \mathrm{L}^{-1}$ potato powder, and $1 \mathrm{~g} \cdot \mathrm{L}^{-1}$ activated charcoal. The $\mathrm{pH}$ of the medium was adjusted as described previously. All cultures were maintained in a culture room at $25 \pm 2{ }^{\circ} \mathrm{C}$ for 6 weeks in dim light $\left(5 \mu \mathrm{mol} \cdot \mathrm{m}^{-2} \cdot \mathrm{s}^{-1}\right)$ provided by cool white fluorescent tubes under a 12-h photoperiod.

Effects of the initial size of the PLB and of physical wounding on their subsequent growth and proliferation. PLBs induced from leaf segments were excised, and single PLBs were sorted into two sizes, small diameter ( 1 to $\leq 2 \mathrm{~mm}$ ) and large diameter ( $>2$ to $3 \mathrm{~mm}$ ), to determine whether the size of the PLB affected later PLB proliferation. Other single PLBs were left whole or were bisected transversely into an upper and lower side before reculture to determine whether physical wounding of a PLB affected PLB proliferation.

For each treatment, $\approx 15$ explants were cultured. In each culture vial, one piece was inoculated in a test tube, and five test tubes served as one replication. Three replications were established for each treatment. Explants were subcultured to fresh medium at 4 weeks of culture. After 2, 4, and 6 weeks of culture, the percentage of proliferating PLBs, shoot germination rate, necrosis rate, number of secondary PLBs per primary PLB, and number of shoots germinating per PLB explants were recorded.

Plant regeneration. After 4 weeks of PLB proliferation (Fig. 1H-I), PLBs were separated and moved to MS basal medium that was modified with half-strength mineral macroelements and microelements and apart from fullstrength $\mathrm{NaFe}$.EDTA, $\mathrm{FeSO}_{4}$, vitamins, and glycine, whereas the other composition was similar to the PLB proliferation medium but lacking potato powder. The conditions also resembled those for PLB proliferation. Plantlets were subcultured every 12 weeks during the culture period (Fig. 1J). All cultures were maintained in a culture room at $25 \pm 2{ }^{\circ} \mathrm{C}$ under a photoperiod of $12 \mathrm{~h}$ provided by cool white fluorescent tubes with $56 \mu \mathrm{mol} \cdot \mathrm{m}^{-2} \cdot \mathrm{s}^{-1}$.

Acclimatization and transplantation. After 14 months of in vitro culture, encompassing 
$\approx 3$ subcultures, fully developed plantlets exhibiting well-developed roots and shoots (measuring $\approx 4 \mathrm{~cm}$ from base of the shoot to leaf tip; Fig. 1J) were acclimatized in open containers for about 2 weeks in a net house. Plantlets were then washed off to remove the medium and transferred to white plastic pots $(5 \mathrm{~cm}$ in diameter) containing sphagnum moss. After 1 year of acclimatization, plants were transplanted to new commercial pots $(9 \mathrm{~cm}$ diameter) containing Pinus radiata bark and coconut husk chips $(1: 1)$ (Fig. 1K).

Statistical analysis. All experiments were arranged by completely randomized design. Statistical analysis of experimental data were conducted using the CoStat 6.1 software package (CoHort Software, Minneapolis, $\mathrm{MN})$. The data expressed as percentages were transformed using arc sine before analysis of variance and converted back to original scale (Compton, 1994). Mean values among treatments were compared using least significant differences multiple range tests at a 5\% level of significance $(P \leq 0.05)$.

\section{Results and Discussion}

PLBs outwardly look like somatic embryos in form and development. Lee et al. (2013) investigated the early stages of PLB formation and confirmed that PLBs are truly somatic embryos. In our experiments, at 16 weeks of culture, the number of explants forming PLBs and the mean number of PLBs per explant were determined. This was done because the PLBs were too small to count, even with a stereomicroscope, at 8 weeks.

Effect of plant height and BA concentration on PLB induction. The induction of PLBs from leaf explants from in vitro-grown donor plantlets was influenced by both plant height and the BA concentration in the induction medium (Table 1). The rate of PLB formation on an explant was generally low. However, The greatest rate of explants forming PLBs was observed on leaves taken from plantlets 1 to 2 $\mathrm{cm}$ in height that were cultured on MS basal medium supplemented with $2 \mathrm{mg} \cdot \mathrm{L}^{-1} \mathrm{BA}$ and $0.5 \mathrm{mg} \cdot \mathrm{L}^{-1} \mathrm{NAA}$ medium. When cultured on medium containing $4 \mathrm{mg} \cdot \mathrm{L}^{-1} \mathrm{BA}$ and 0.5 $\mathrm{mg} \cdot \mathrm{L}^{-1} \mathrm{NAA}$, leaves from plantlets 1 to $2 \mathrm{~cm}$ in height induced an average of 24.0 PLBs on $13.3 \%$ of the explants. The percentage of explants forming PLBs was significantly different between leaf explants taken from plantlets of differing heights $(1-2,2-3$, and 3-4 $\mathrm{cm})$. In contrast, different BA concentrations did not significantly influence the rate of PLB induction. Therefore, it seems that the initial appearance of a PLB is most influenced by the maturity of the leaf. Similarly, only explants from juvenile Aerides maculosum plants were capable of inducing PLBs (Murthy and Pyati, 2001). In Aerides crispum, juvenile explants such as young leaves (Sheelavanthmath et al., 2005) more efficiently induced PLBs and showed better regeneration of whole plants (De and Sil, 2015). These differential responses of mature and juvenile leaf explants under equal nutritional conditions seem to indicate the importance of the source of explants (Murthy and Pyati, 2001). In contrast, Oncidium Gower Ramsey in vitro-grown donor plantlets 5 to $7 \mathrm{~cm}$ in height yielded both the greatest rate of somatic embryo proliferation and more somatic embryos per explant than did plants 2 to $4 \mathrm{~cm}$ in height (Chen et al., 1999). In this study, the low number of explants forming PLBs may be because leaves from different position on plantlet were taken as explants. However, this prompted an investigation into the effects of leaf position on PLB induction.

Effect of leaf position and $B A$ concentration on PLB induction. The effects of leaf position within the donor plantlet at two different BA concentrations on PLB induction were tested using in vitro-grown donor plantlets of 1 to $2 \mathrm{~cm}$ in height (Table 2). No PLBs formed when outer leaves were grown on MS basal medium supplemented with $0.5 \mathrm{mg} \cdot \mathrm{L}^{-1} \mathrm{NAA}$ and 2 or $4 \mathrm{mg} \cdot \mathrm{L}^{-1} \mathrm{BA}$. Only inner expanding leaves (first to third) cultured on MS basal medium supplemented with $4 \mathrm{mg} \cdot \mathrm{L}^{-1} \mathrm{BA}$ and 0.5 $\mathrm{mg} \cdot \mathrm{L}^{-1}$ NAA resulted in PLB induction, at an average of 25.5 PLBs per explant. Likewise, young leaves from Coelogyne flaccida showed better regeneration relative to older explants, owing to their less-rigid cell walls, and retained competence for regeneration and proliferation (De and Sil, 2015). In contrast, in Acempe praemorsa (Roxb.) Blatter and McCann, both young expanding leaves (first and second) and older expanding leaves (fifth and sixth) failed to regenerate shoot buds, whereas the third and fourth leaves could (Nayak et al., 1997). Meanwhile, Seeni and Latha (1992) have reported that all leaves from in vitro-grown shoots of Renanthera imschootiana Rolfe produced shoot buds in culture. This rate of success and low rate of PLB formation was similar to results in Acampe (Nayak et al., 1997), Aerides (Murthy, 2005; Murthy and Pyati, 2001), Dendrobium (Chung et al., 2005), Oncidium (Chen et al., 1999; Mayer et al., 2010), and Phalaenopsis (Balilashaki et al., 2015; Chen and Chang, 2006; Kuo et al., 2005; Park et al., 2002a). Nayak et al. (1997) showed that explants exuded copious amounts of phenolic compounds within 3 to $5 \mathrm{~d}$ of culture and that transfer to fresh medium at 7-d intervals could decrease the amount of exudates to overcome the inhibition of PLB formation.

Cytokinins play important roles in the control of plant development, especially in plant cell division (George et al., 2008). Trigiano and Gray (2000) reported that BA has remarkably stronger cytokinin activity than the naturally cytokinin such zeatin. Moreover, BA has been shown to efficiently induce

Table 1. Effects of plant height on PLB induction of Tolumnia Snow Fairy after 16 weeks of culture. ${ }^{z}$

\begin{tabular}{lcccc}
\hline BA $\left(\mathrm{mg} \cdot \mathrm{L}^{-1}\right)$ & $\mathrm{Ht}$ & PLB induction $(\%)^{\mathrm{y}}$ & ${\text { Necrosis }(\%)^{\mathrm{y}}}$ & PLBs/explant \\
\hline 2 & $1-2 \mathrm{~cm}$ & $16.7 \pm 9.5 \mathrm{a}$ & $33.3 \pm 15.2 \mathrm{a}$ & $17.5 \mathrm{ab}$ \\
& $2-3 \mathrm{~cm}$ & $10.0 \pm 4.5 \mathrm{ab}$ & $43.3 \pm 6.1 \mathrm{a}$ & $14.3 \mathrm{bc}$ \\
& $3-4 \mathrm{~cm}$ & $3.3 \pm 3.3 \mathrm{ab}$ & $26.7 \pm 9.9 \mathrm{a}$ & $9.0 \mathrm{bc}$ \\
4 & $1-2 \mathrm{~cm}$ & $13.3 \pm 4.2 \mathrm{a}$ & $23.3 \pm 9.5 \mathrm{a}$ & $24.0 \mathrm{ab}$ \\
& $2-3 \mathrm{~cm}$ & $3.3 \pm 3.3 \mathrm{ab}$ & $43.3 \pm 9.5 \mathrm{a}$ & $41.0 \mathrm{ab}$ \\
& $3-4 \mathrm{~cm}$ & $0.0 \pm 0.0 \mathrm{~b}$ & $36.7 \pm 8.0 \mathrm{a}$ & $0.0 \mathrm{c}$ \\
BA $^{\mathrm{x}}$ & & $\mathrm{NS}$ & $\mathrm{NS}$ & $\mathrm{NS}$ \\
Plant height $^{\mathrm{x}}$ & & $*$ & $\mathrm{NS}$ & $*$ \\
BA vs. plant height $^{\mathrm{x}}$ & & $\mathrm{NS}$ & $\mathrm{NS}$ & $\mathrm{NS}$ \\
\hline
\end{tabular}

${ }^{\mathrm{z}}$ Six replicates each containing five test tubes (one explant per test tube) were performed for each treatment and cultured on MS basal medium supplemented with different of BA concentrations with $0.5 \mathrm{mg} \cdot \mathrm{L}^{-1}$ NAA.

${ }^{\mathrm{y}}$ Percentage data used angular transformation before analysis, and means \pm SE within a column followed by different letters are significantly different according to least significant differences multiple range test at $P \leq 0.05$.

${ }^{\mathrm{x}}$ Significance was determined by analysis of variance $(1-2 \mathrm{~cm}:>1$ to $<2 ; 2-3 \mathrm{~cm}:>2$ to $<3$; and $3-4 \mathrm{~cm}:>3$ to $<4)$.

$\mathrm{PLB}=$ protocorm like-body; $\mathrm{NS}=$ not significant; MS = Murashige and Skoog.

Table 2. Effects of leaf position on PLB induction of Tolumnia Snow Fairy after 16 weeks of culture. ${ }^{z}$

\begin{tabular}{lcccc}
\hline BA $\left(\mathrm{mg} \cdot \mathrm{L}^{-1}\right)$ & Positions & PLB induction $(\%)^{\mathrm{y}}$ & ${\text { Necrosis }(\%)^{\mathrm{y}}}$ & PLBs/explant \\
\hline 2 & Inner & $0.0 \pm 0.0 \mathrm{~b}$ & $36.7 \pm 9.5 \mathrm{a}$ & $0.0 \mathrm{~b}$ \\
& Outer & $0.0 \pm 0.0 \mathrm{~b}$ & $26.7 \pm 8.4 \mathrm{ab}$ & $0.0 \mathrm{~b}$ \\
4 & Inner & $16.7 \pm 6.1 \mathrm{a}$ & $10.0 \pm 4.5 \mathrm{~b}$ & $25.5 \mathrm{a}$ \\
& Outer & $0.0 \pm 0.0 \mathrm{~b}$ & $26.7 \pm 6.7 \mathrm{ab}$ & $0.0 \mathrm{a}$ \\
BA $^{\mathrm{x}}$ & & $* *$ & $\mathrm{NS}$ & $* * *$ \\
Leaf position $^{\mathrm{x}}$ & & $* *$ & $\mathrm{NS}$ & $* * *$ \\
BA vs. Leaf position $^{\mathrm{x}}$ & $* *$ & $\mathrm{NS}$ & $* * *$ \\
\hline
\end{tabular}

${ }^{\mathrm{z}}$ Six replicates each containing five test tubes (one explant per test tube) were performed for each treatment and cultured on MS basal medium supplemented with different of BA concentrations with $0.5 \mathrm{mg} \cdot \mathrm{L}^{-1}$ NAA. Leaves were taken from in vitro-grown donor plantlets of 1 to $2 \mathrm{~cm}$ in height.

${ }^{\mathrm{y}}$ Percentage data used angular transformation before analysis, and means $\pm \mathrm{SE}$ within a column followed by the same letter are not significantly different according least significant differences multiple range test at $P \leq 0.05$

${ }^{\mathrm{x}}$ Significance was determined by analysis of variance.

$\mathrm{PLB}=$ protocorm like-body; $\mathrm{NS}=$ not significant; $\mathrm{MS}=$ Murashige and Skoog. 
PLBs from leaf explants (Murthy and Pyati, 2001; Sheelavanthmath et al., 2005) and to play an important role in plant regeneration from leaf explants in tissue culture of other orchid species (Deb and Pongener, 2013; Janarthanam and Seshadri, 2008; Martin and Madassery, 2006; Nayak et al., 1997). Our result showed that both 2 and $4 \mathrm{mg} \cdot \mathrm{L}^{-1} \mathrm{BA}$ with $0.5 \mathrm{mg} \cdot \mathrm{L}^{-1} \mathrm{NAA}$ in the medium promoted the formation of PLBs, especially when leaf explants were cultured on MS basal medium supplemented with $4 \mathrm{mg} \cdot \mathrm{L}^{-1}$ BA and 0.5 $\mathrm{mg} \cdot \mathrm{L}^{-1}$ NAA. Several orchid studies on PLB induction and shoot regeneration from leaf explants used a range of BA concentrations, between 1 and $10 \mathrm{mg} \cdot \mathrm{L}^{-1}$ (Chen and Chang, 2001; Chen and Hong, 2012; Chung et al., 2005; Kuo et al., 2005; Martin and Madassery, 2006; Murthy and Pyati, 2001; Nayak et al., 1997; Park et al., 2002b; Sheelavanthmath et al., 2005; Su et al., 2006). However, high levels of BA also could inhibit PLB induction (Murthy and Pyati, 2001) as well as which prefer to induce adventitious shoots formation (Narayana et al., 2016; Trigiano and Gray, 2000). Furthermore, Hongthongkham and Bunnag (2014) reported that BA alone induced shoot formation rather than PLB, whereas low concentrations of auxin promoted PLB growth (Khoddamzadeh et al., 2011) and reduced plantlet conversion (Gow et al., 2010).

Microscopic observation of leaf-derived PLBs. PLB formation is a unique characteristic of Orchidaceae. A structure can be called a PLB from the initiation of globular swelling to appearance of shoot primordia without any roots (Batygina et al., 2003). Histological and SEM observations revealed in inner position of leaf on MS basal medium supplemented with $4 \mathrm{mg} \cdot \mathrm{L}^{-1} \mathrm{BA}$ and 0.5 $\mathrm{mg} \cdot \mathrm{L}^{-1}$ NAA medium that PLBs (primary embryo) originated from epidermal cell division (Fig. 2A), whereas meristematic cells were densely stained and had a smaller size than the leaf cells. In some cases, secondary embryos developed from outer layers of the primary embryos (Fig. 2B). After 16 weeks of culture, multiple PLBs were visible (Fig. 2C). Antony et al. (2014) used histological and SEM observations to report that PLBs can develop from a wounded surface of an explant and can be converted into plantlets, as the PLBs consisted of multiple meristematic centers then can be gradually differentiated into shoot, leaf, and root. Our results support the various other reports that demonstrated that PLBs can form from the epidermal cell layers (Chen and Chang, 2004, 2006; Khoddamzadeh et al., 2011; Kuo et al., 2005). Moreover, most PLBs formed at the base of the explant. Efficient PLB induction on the leaf base has been reported for several other orchid species, such as Aerides (Murthy and Pyati, 2001), Coelogyne (De and Sil, 2015), Cymbidium (Deb and Pongener, 2013), Dendrobium (Martin and Madassery, 2006), Oncidium (Chen and Hong, 2012), and Phalaenopsis (Gow et al., 2009; Park et al., 2002b). Moreover, our results support those showing that no PLB induction occurred on either side of the leaf explant between the tip and the cut end (Chung et al., 2007). Although some secondary PLBs did form during the PLB induction stage, the number of PLBs that were obtained was still low, prompting the requirement of a PLB proliferation stage to increase PLB numbers.

Effects of PLB size and physical wounding on PLB proliferation. Julkiflee et al. (2014) revealed that PGR-free medium could increase PLB proliferation. In addition, $\mathrm{Ng}$ and Saleh (2011) suggested that PGR-free medium could obtain genetically stable PLBs. In recent years, secondary PLB development from PLBs has been shown for various orchids, including Dendrobium (Julkiflee et al., 2014), Doritaenopsis (Amaki and Higuchi, 1989), and Phalaenopsis (Huang et al., 2014; Khoddamzadeh et al., 2011). However, the results in this study showed that both large and small PLBs formed secondary PLBs (PLB proliferation) at nearly the same rates over 2,4 , and 6 weeks of culture (Fig. 3). However, there was a difference in generation of secondary PLBs after the first subculture. Small PLBs, 1 to $\leq 2 \mathrm{~mm}$ in diameter, tended to continue generation through 4 weeks after their subculture, whereas PLBs $>2$ to $3 \mathrm{~mm}$ in diameter tended to deteriorate 4 weeks after subculture. In addition, after subculture, shoot germination was observed in PLBs of both sizes. PLB necrosis also was reported by Bustam et al. (2014). Our study indicated that PLBs 1 to $\leq 2 \mathrm{~mm}$ in diameter could proliferate over a longer term, with no deterioration until 6 weeks of culture. Therefore, we selected this size PLB for the physical wounding investigation.

PLBs of 1 to $\leq 2 \mathrm{~mm}$ were physically wounded by cutting them in half, and PLB proliferation was measured after 6 weeks of culture (Table 3). Whole PLBs achieved a $33.3 \%$ PLB proliferation rate, in comparison with a $40 \%$ PLB proliferation rate for the upper half of bisected PLBs (Fig. 4A-B). The PLB proliferation rates and the average
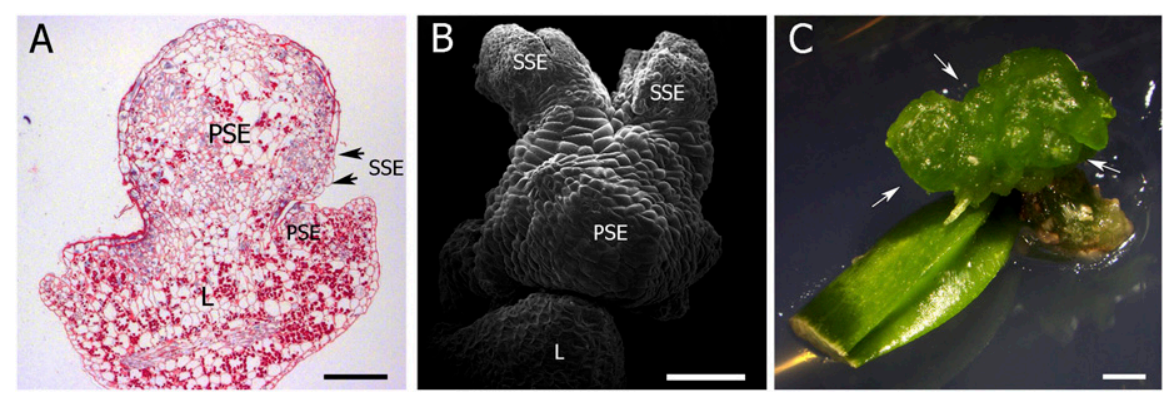

Fig. 2. Induction of protocorm like-body (PLB) from leaves taken from the inner position of in vitro-grown plantlets of Tolumnia Snow Fairy. After 16 weeks of culture on PLB induction medium, (A) PLBs or primary somatic embryos (PSEs) directly from the basal side of leaf explants (L) with secondary somatic embryo (SSE) on Murashige and Skoog basal medium containing with $4 \mathrm{mg} \cdot \mathrm{L}^{-1} \mathrm{BA}$ and 0.5 $\mathrm{mg} \cdot \mathrm{L}^{-1}$ NAA (bar $200 \mu \mathrm{m}$ ). (B) SSE formed from the PSE (bar $\left.500 \mu \mathrm{m}\right)$. (C) Multiplication of some PLBs occurred while still on PLB induction medium (arrow) (bar $1 \mathrm{~mm}$ ).

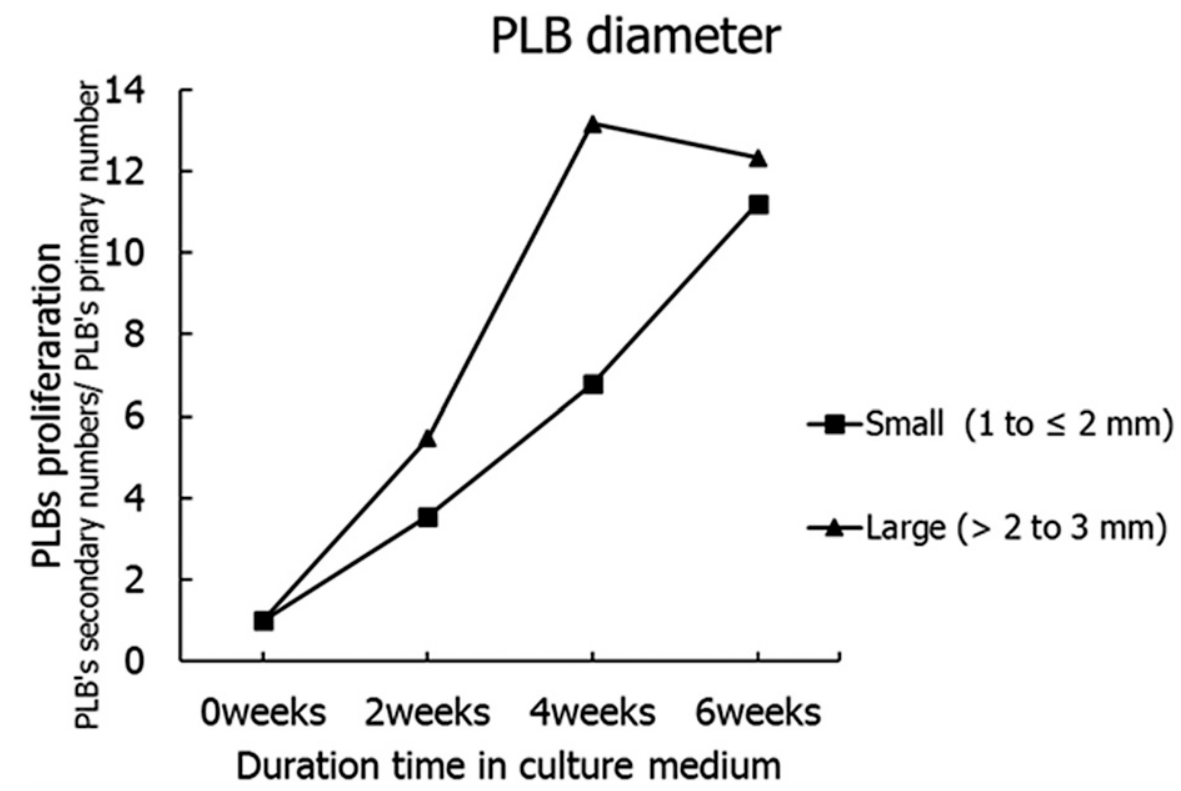

Fig. 3. The effects of protocorm like-body (PLB) diameter on secondary proliferation of Tolumnia Snow Fairy. 1- to $\leq 2-\mathrm{mm}$ diameter PLBs and $>2$ - to 3-mm diameter PLBs were tracked for 6 weeks for PLB proliferation (i.e., secondary PLBs per primary PLB). 
numbers of secondary PLBs were not significantly different between the upper half and whole PLBs. In addition, secondary PLBs produced an additional 3.1 to 3.5 PLBs. In contrast, no secondary PLBs were observed from the lower half of PLBs. This study indicated that only whole PLBs and the upper sides of PLBs could form secondary PLBs.

This may be because the whole PLB and the upper side of the PLB still had many cell clumps around apical meristems that it would protrude and develop after 2 weeks. Others have shown that the lower halves of bisected PLBs are more efficient in the proliferation of secondary PLBs (Amaki and Higuchi, 1989; Huang et al., 2014; Tanaka, 1987).

Table 3. Effect of physical wounding of PLB by bisection on PLB proliferation, shoot germination and necrosis rate of Tolumnia Snow Fairy after 6 weeks of culture. ${ }^{\mathrm{z}}$

\begin{tabular}{|c|c|c|c|c|c|}
\hline $\begin{array}{l}\text { Physical wounding } \\
\text { of PLB }\end{array}$ & $\begin{array}{c}\text { PLBs } \\
\text { proliferation }(\%)^{\mathrm{y}}\end{array}$ & $\begin{array}{c}\text { Shoot } \\
\text { germination }(\%)^{\mathrm{y}}\end{array}$ & $\begin{array}{l}\text { Necrosis } \\
(\%)^{\mathrm{y}}\end{array}$ & PLBs/explant & Shoots/explant \\
\hline Whole PLB & $33.3 \pm 6.7 \mathrm{a}$ & $33.3 \pm 6.7 \mathrm{a}$ & $60.0 \pm 11.5 \mathrm{a}$ & $3.5 \mathrm{a}$ & $0.7 \mathrm{a}$ \\
\hline Upper & $40.0 \pm 11.5 \mathrm{a}$ & $40.0 \pm 11.5 \mathrm{a}$ & $60.0 \pm 11.5 \mathrm{a}$ & $3.1 \mathrm{a}$ & $1.3 \mathrm{a}$ \\
\hline Lower & $0.0 \pm 0.0 \mathrm{~b}$ & $0.0 \pm 0.0 \mathrm{~b}$ & $86.7 \pm 6.7 \mathrm{a}$ & $0.0 \mathrm{a}$ & $0.0 \mathrm{a}$ \\
\hline
\end{tabular}

${ }^{\mathrm{z}}$ Three replicates each containing five test tubes (one explant per test tube) were performed for each treatment and cultured on MS basal medium modified for PLB proliferation.

${ }^{\mathrm{y}}$ Percentage data were angular transformed before analysis and means \pm SE within a column followed by the different letters are significantly different according least significant differences multiple range test at $P \leq 0.05$.

$\mathrm{PLB}=$ protocorm like-body; $\mathrm{MS}=$ Murashige and Skoog
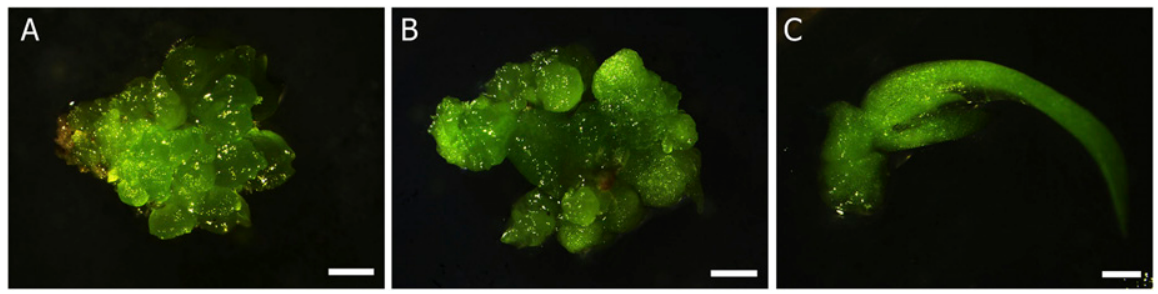

Fig. 4. The effects of physical wounding of primary protocorm like-bodies (PLBs; $1-2 \mathrm{~mm}$ ) on secondary PLB proliferation and shoot germination in the presence of cytokinins after 6 weeks of PLB culture on PLB proliferation medium. (A) Whole PLB and (B-C) upper half of bisected PLBs (bar $1 \mathrm{~mm}$ ).
Six weeks after subculture of the PLBs to the same medium, the shoot germination rate was $33.3 \%$ with an average of 3.5 shoots per whole PLB, with corresponding rates of $40 \%$ with 3.1 shoots for the upper PLB halves. The PLB upper half formed primordial leaves instead of PLBs (Fig. 4C). Amaki and Higuchi (1989) indicated that the dorsal segment of a PLB had a tendency to generate plantlets, but a basal segment could not. Because a single PLB was divided by scalpel, the lower halves of the PLBs easily died. Bustam et al. (2014) reported that PLBs became brown and that most failed to proliferate further when compact clumps of PLBs were separated by scalpel and forceps. This result revealed that PLBs tended to die easily and that their viability decreased in long-term culture.

Regeneration of PLBs into plantlets. After 16 weeks of culture, some PLBs (still attached to leaf explants) were transferred to proliferation medium for multiplication and were subcultured to fresh medium at 7-d intervals. Shoot buds first appeared as small, green globular swellings during PLB proliferation and eventually developed into shoots (Fig. 5A). After 1 month of proliferation, PLBs were removed from the explant and moved to regeneration medium for further PLB development and plant regeneration (Fig. 5B). Plant regeneration has been induced from PLBs from various orchids (Balilashaki et al., 2015; Chen and Chang, 2004; De and Sil, 2015; Mayer et al., 2010; Teng et al., 1997). Since PLBs are true orchid embryos (Lee et al., 2013), these structures can easily convert into plantlets (Ng and Saleh, 2011).
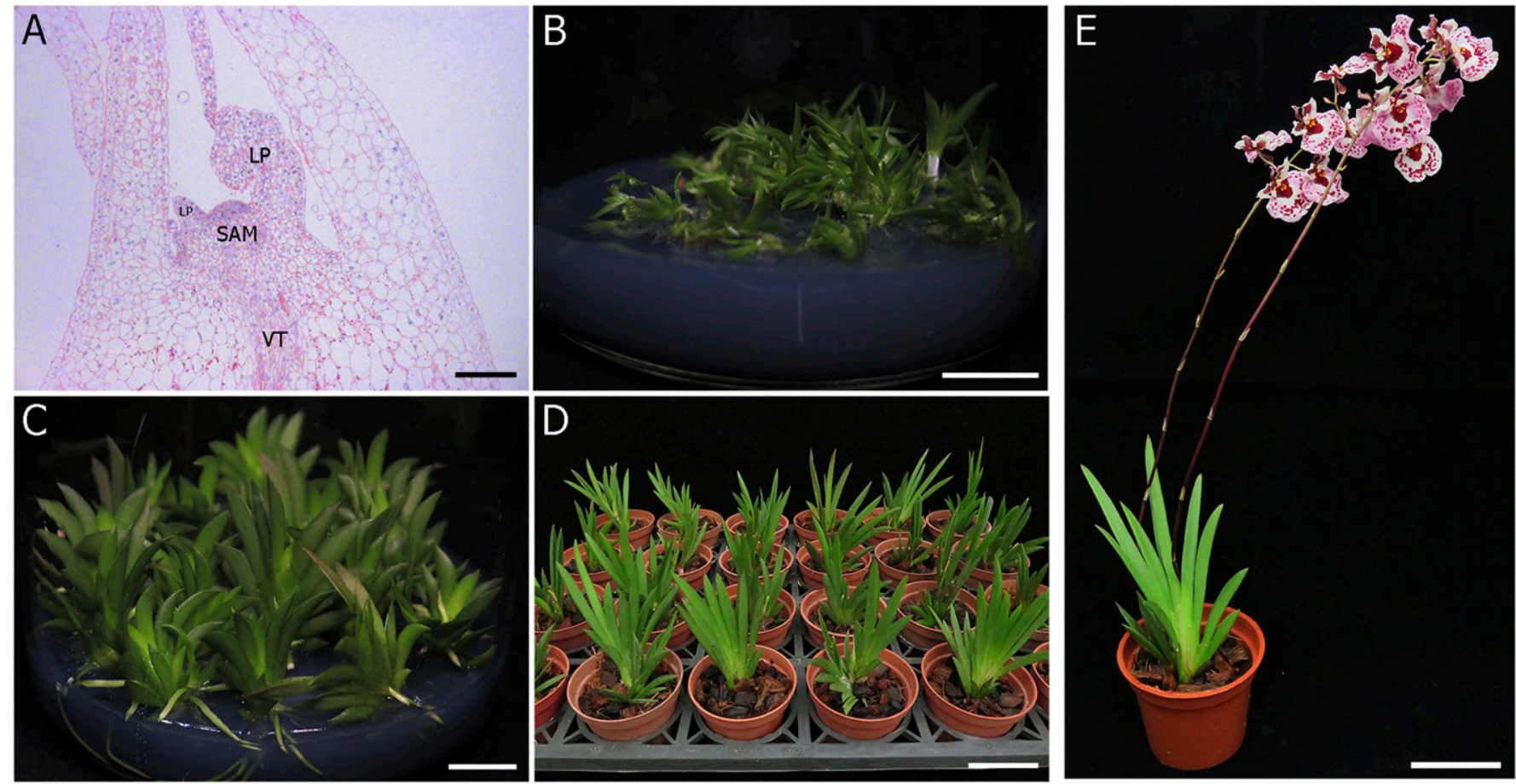

Fig. 5. Plant regeneration from leaf explants taken from the inner position of in vitro-grown Tolumnia Snow Fairy. Different steps include (A) development of a mature protocorm-like body (PLB) with shoot apical meristem (SAM), leaf primordia (LP), and vascular tissue (VT) (bar $200 \mu \mathrm{m}$ ); (B) multiplication of PLBs and regeneration of a large number of plantlets after 6 months $($ bar $1 \mathrm{~cm})$; and $(\mathbf{C})$ individual plantlets cultured on plant regeneration medium were grown in open tissue culture plates in a net greenhouse (bar $1 \mathrm{~cm}$ ). (D) Regenerated plants in pots containing pine bark and coconut husk chips (1:1) after 1 year of acclimatization (bar $5 \mathrm{~cm}$ ). (E) Some plants flowered 1 year after transfer to pots. (bar $5 \mathrm{~cm}$ ). 
Acclimation of in vitro-grown plantlets. After 3 rounds of subculture on plant regeneration medium, fully developed plantlets with well-developed roots and shoots, measuring on average 4 to $5 \mathrm{~cm}$ tall, were acclimatized for about 2 weeks on their tissue culture medium in a net house (Fig. 5C). Plants were then transferred to white plastic pots containing sphagnum moss. One year after transplantation, plants were transferred to pine bark and coconut husk chips in plastic commercial pots. These plants grew well (Fig. 5D), and transplants survived at rates of nearly $73 \%$, for explants taken from 1 - to 2 -cm tall plants and nearly $79 \%$, for explants taken from inner leaf positions. Some mature plants flowered after 1 year (Fig. 5E).

In the method described here, Tolumnia orchid explants first formed PLBs during in vitro induction, followed by PLB proliferation and plant regeneration after transfer to PGR-free medium for proliferation and plant regeneration. Under natural conditions, the period from protocorm-like bodies induction to flowering of the Tolumnia Snow Fairy is 2 years. This protocol is easy to carry out, simple, and can provide large numbers of plants for mass propagation in a short time. Finally, all procedures may be conveniently applied for mass multiplication of Tolumnia orchids.

\section{Literature Cited}

Aldrich, A. 1994. Orchid care "Equitant oncidium”. Amer. Orchid Soc. Bull. 63:904-907.

Amaki, W. and H. Higuchi. 1989. Effects of dividing on the growth and organogenesis of protocorm-like bodies in Doritaenopsis. Scientia Hort. 39:63-72.

Antony, J.J.J., J. Sundarasekar, X. Rathinam, K. Marimuthu, and S. Subramaniam. 2014. Microscopical analysis of in vitro Mokara Broga Giant orchid's PLBs. Emir. J. Food Agr. 26(1):73-81.

Baker, M.L. and C.O. Baker. 2006. Orchid species culture Oncidium/Odontoglossum alliance. Timber Press, Portland, OR.

Balilashaki, K., M. Vahedi, and R. Karimi. 2015. In vitro direct regeneration from node and leaf explants of Phalaenopsis cv. 'Surabaya'. Plant Tissue Cult. Biotechnol. 25:193-205.

Batygina, T.B., E.A. Bragina, and V.E. Vasilyeva. 2003. The reproductive system and germination in orchids. Acta Biol. Cracov., Ser. Bot. 45:21-34.

Bustam, B.M., K. Dixon, and E. Bunn. 2014. Proliferation and harvesting of secondary protocorms as a novel means for improving propagation of terrestrial orchids. Austral. J. Bot. 62:614-621.

Chang, C., W.H. Hu, Y.C. Chen, Y.L. Su, and Y.T. Chiu. 2010. In vitro flowering and mating system of Eulophia graminea Lindl. Bot. Stud. 51:357-362.

Chen, J.T. and W.C. Chang. 2001. Effects of auxins and cytokinins on direct somatic embryogenesis on leaf explants of Oncidium Gower Ramsey. Plant Growth Regulat. 34:229-232.

Chen, J.T. and W.C. Chang. 2003. 1-aminocyclopropane1-carboxylic acid enhanced direct somatic embryogenesis from Oncidium leaf cultures. Biol. Plant. 46:455-458.

Chen, J.T. and W.C. Chang. 2004. TIBA affects the induction of direct somatic embryogenesis from leaf explants of Oncidium. Plant Cell Tissue Organ Cult. 79:315-320.

Chen, J.T. and W.C. Chang. 2006. Direct somatic embryogenesis and plant regeneration from leaf explants of Phalaenopsis amabilis. Biol. Plant. 50:169-173.

Chen, J.T., C. Chang, and W.C. Chang. 1999. Direct somatic embryogenesis on leaf explants of Oncidium Gower Ramsey and subsequent plant regeneration. Plant Cell Rpt. 19:143-149.

Chen, J.T. and P.I. Hong. 2012. Cellular origin and development of secondary somatic embryos in Oncidium leaf cultures. Biol. Plant. 56:215220.

Chookoh, N. 2015. Tissue culture and progeny selection of Tolumnia orchid. MS Thesis, Natl. Chung Hsing Univ., Taichung.

Chookoh, N., Y.T. Chiu, and C. Chang. 2016. Effects of flower stalks node positions and BA concentrations on shoot bud formation of Tolumnia Snow Fairy in vitro. Hort. NCHU. 41(1):105-115.

Chugh, S., S. Guha, and I.U. Rao. 2009. Micropropagation of orchids: A review on the potential of different explants. Scientia Hort. 122:507-520.

Chung, H.H., J.T. Chen, and W.C. Chang. 2005. Cytokinins induce direct somatic embryogenesis of Dendrobium Chiendmai Pink and subsequent plant regeneration. In Vitro Cell. Dev. Biol. Plant 41:765-769.

Chung, H.H., J.T. Chen, and W.C. Chang. 2007. Plant regeneration through direct somatic embryogenesis from leaf explants of Dendrobium. Biol. Plant. 51:346-350.

Chung, J.P., C.Y. Huang, and T.E. Dai. 2010. Spectral effects on embryogenesis and plantlet growth of Oncidium Gower Ramsey. Scientia Hort. 124:511-516.

Compton, M.E. 1994. Statistical methods suitable for the analysis of plant tissue culture data. Plant Cell Tissue Organ Cult. 37:217-242.

De, K.K. and S. Sil. 2015. Protocorm-like bodies and plant regeneration from foliar explants of Coelogyne flaccida, a horticulturally and medicinally important endangered orchid of Eastern. Lankesteriana 15: 151-158.

Deb, C.R. and A. Pongener. 2013. In vitro regenerative competence of foliar explants of Cymbidium aloifolium (L.) Sw. and C. iridioides $\mathrm{D}$. Don: Two horticultural important orchids. Indian J. Biotechnol. 12:402-408.

Decruse, S.W., A. Gangaprasad, S. Seeni, and V.S. Menon. 2003. A protocol for shoot multiplication from foliar meristem of Vanda spathulata (L.). Spreng. Indian J. Expt. Biol. 41:924-927.

George, E.F., M.A. Hall, and G.J. De Klerk. 2008. Plant propagation by tissue culture. 3rd ed. Springer, Wageningen, The Netherlands.

Goswami, K., S. Yasmin, K.M. Nasiruddin, F Khatun, and J. Akte. 2015. In vitro regeneration of Dendrobium sp. of orchid using leaf tip as explant. J. Environ. Sci. Nat. Resour. 8:75-78.

Gow, W.P., J.T. Chen, and W.C. Chang. 2009. Effects of genotype, light regime, explant position and orientation on direct somatic embryogenesis from leaf explants of Phalaenopsis orchids. Acta Physiol. Plant. 31:363369.

Gow, W.P., J.T. Chen, and W.C. Chang. 2010. Enhancement of direct somatic embryogenesis and plantlet growth from leaf explants of Phalaenopsis by adjusting culture period and explant length. Acta Physiol. Plant. 32:621627.

Hong, P.I., J.T. Chen, and W.C. Chang. 2008. Promotion of direct somatic embryogenesis of
Oncidium by adjusting carbon sources. Biol. Plant. 52:597-600.

Hongthongkham, J. and S. Bunnag. 2014. In vitro propagation and cryopreservation of Aerides odorata Lour. (Orchidaceae). Pak. J. Biol. Sci. 17:608-618.

Huang, Y.W., Y.J. Tsai, T.C. Cheng, J.J. Chen, and F.C. Chen. 2014. Physical wounding and ethylene stimulated embryogenic stem cell proliferation and plantlet regeneration in protocorm-like bodies of Phalaenopsis orchids. Genet. Mol. Res. 13(4):9543-9557.

Janarthanam, B. and S. Seshadri. 2008. Plantlet regeneration from leaf derived callus of Vanilla planifolia Andr. In Vitro Cell. Dev. Biol. Plant 44:84-89.

Julkiflee, A.L., J. Uddain, and S. Subramaniam. 2014. Efficient micropropagation of Dendrobium Sonia-28 for rapid PLBs proliferation. Emir. J. Food Agric. 26(6):545-551.

Khoddamzadeh, A.A., U.R. Sinniah, M.A. Kadir, S.B. Kadzimin, M. Mahmod, and S. Sreeeramanan. 2011. In vitro induction and proliferation of protocorm-like bodies from leaf segments of Phalaenopsis bellina (Rchb.f.) Christenson. Plant Growth Regulat. 65:381387.

Kuo, H.L., J.T. Chen, and W.C. Chang. 2005. Efficient Plant regeneration through direct somatic embryogenesis from leaf explants of 'Little Steve'. In Vitro Cell. Dev. Biol. Plant 41:453-456.

Lee, Y.I., S.T. Hsu, and E.C. Yeung. 2013. Orchid protocorm-like bodies are somatic embryos. Amer. J. Bot. 100:2121-2131.

Martin, K.P. and J. Madassery. 2006. Rapid in propagation of Dendrobium hybrids through direct shoot formation from foliar explants, and protocorm-like bodies. Scientia Hort. 108:9599.

Mata-Rosas, M., R.J. Baltazar-Garcia, and V.M. Chavez-Avila. 2011. In vitro regeneration through direct organogenesis from protocorms of Oncidium tigrinum Llave and Lex. (Orchidaceae), an endemic and threatened Mexican species. HortScience 46:11321135.

Mayer, J.L.S., G.C. Stancato, and B. AppezzatoDa-Glória. 2010. Direct regeneration of protocorm-like bodies (PLB) from leaf apices of Oncidium flexuosum Sims (Orchidaceae). Plant Cell Tissue Organ Cult. 103:411-416.

Mengxi, L., X. Zhigang, Y. Yang, and F. Yijie. 2011. Effects of different spectral lights on Oncidium PLB induction, proliferation, and plant regeneration. Plant Cell Tissue Organ Cult. 106:1-10.

Murashige, T. and F. Skoog. 1962. A revised medium for rapid growth and bioassays with tobacco tissue culture. Physiol. Plant. 15:473-497.

Murthy, H.N. 2005. In vitro multiplication and ecorehabilitation of rare orchid Aerides crispum, p. 191-192. The role of biotechnology. Villa Gualino, Turin, Italy. 5-7 March.

Murthy, H.N. and A.N. Pyati. 2001. Micropropagation of Aerides maculosum Lindl. (Orchidaceae). In Vitro Cell. Dev. Biol. Plant 37:223-226.

Narayana, P.S., D. Varalakshmi, and T. Pullaiah. 2016. Research methodology in plant science. Scientific Publishers, Jodhpur, India.

Nayak, N.R., S. Patnaik, and S.P. Rath. 1997. Direct shoot regeneration from foliar explants of an epiphytic orchid, Acampe praemorsa (Roxb.) Blatter and McCann. Plant Cell Rpt. 16:583-586.

$\mathrm{Ng}$, C.Y. and N.M. Saleh. 2011. In vitro propagation of Paphiopedilum orchid through 
formation of protocorm-like bodies. Plant Cell Tissue Organ Cult. 105:193-202.

Ng, C.Y., N.M. Saleh, and F.Q. Zaman. 2010. In vitro multiplication of the rare and endangered slipper orchid, Paphiopedilum rothschildianum (Orchidaceae). Afr. J. Biotechnol. 9(14):20622068.

Paek, Y.P., E.J. Hahn, and S.Y. Park. 2011. Micropropagation of Phalaenopsis orchids via protocorms and protocorm-like bodies. Methods Mol. Biol. 710:293-306.

Park, S.Y., H.N. Murthy, and K.Y. Paek. 2002a. Rapid propagation of Phalaenopsis from floral stalk-derived leaves. In Vitro Cell. Dev. Biol. Plant 38:168-172.

Park, S.Y., E.C. Yeung, D. Chakrabarty, and K.Y. Paek. 2002b. An efficient direct induction of protocorm-like bodies from leaf subepidermal cells of Doritaenopsis hybrid using thin-section culture. Plant Cell Rpt. 21:46-51.

Seeni, S. and P.G. Latha. 1992. Foliar regeneration of the endangered red vanda, Renanthera imschootiana Rolfe (Orchidaceae). Plant Cell Tissue Organ Cult. 29:167-172.

Sheelavanthmath, S.S., H.N. Murthy, B.P. Hema, E.J. Hahn, and K.Y. Paek. 2005. High frequency of protocorm like bodies (PLB) induction and plant regeneration from protocorm and leaf sections of Aerides crispum. Scientia Hort. 106:395-401.

Shen, H.J., J.T. Chen, H.H. Chung, and W.C. Chang. 2018. Plant regeneration via direct somatic embryogenesis from leaf explants of Tolumnia Louise Elmore 'Elsa'. Bot. Stud. 59:4.

Su, Y.J., J.T. Chen, and W.C. Chang. 2006 Efficient and repetitive production of leafderived somatic embryos of Oncidium. Biol. Plant. 50:107-110.

Tan, B.C., C.F. Chin, and P. Alderson. 2011. Optimization of plantlet regeneration from leaf and nodal derived callus of Vanilla planifolia Andrews. Plant Cell Tissue Organ Cult. 105:457-463.
Tanaka, M. 1987. Studies on the clonal propagation of Phalaenopsis through in vitro culture. Mem. Fac. Agr. Kagawa Univ. 49:1-85.

Teng, W.L., L. Nicholson, and M.C. Teng. 1997. Micropropagation of Spathoglottis plicata. Plant Cell Rpt. 16:831-835.

Trigiano, R.N. and D.J. Gray. 2000. Plant tissue culture concepts and laboratory exercises. 2nd ed. CRC Press LLC, Boca Raton, FL.

Yeung, E.C. 1984. Histological and histochemical staining procedures, p. 689-697. In: I.K. Vasil (ed.). Cell culture and somatic cell genetics of plants. Vol. 1. Laboratory procedures and their applications. Academic Press, Orlando, FL.

Yeung, E.C. and C.K.W. Chan. 2015. The glycol methacrylate embedding resins-Technovit 7100 and 8100, p. 67-82. In: E.C. Yeung, C. Stasolla, B.Q. Huang, and M.J. Sumner (eds.). Plant microtechniques and protocols. Springer, Cham, Switzerland. 